\title{
CLOSED VASCULAR INJURY OF THE FINGER
}

\author{
G. E. B. GIDDINS, P. D. BURGE
}

Injuries of the digital arteries of the hand are usually due to open wounds. We report three cases of rupture of both digital arteries of a finger associated with a closed injury.

Case 1. A 33-year-old man was feeding a rope to a waterskier with his left hand when the boat accelerated suddenly and his ulnar three digits were injured by a loop of the rope. He sustained a grade- 1 open fracture of the proximal phalanx of the little finger (Fig. 1). The ring finger was not fractured but was dusky and cool.

The ring finger was explored on the day of injury. The

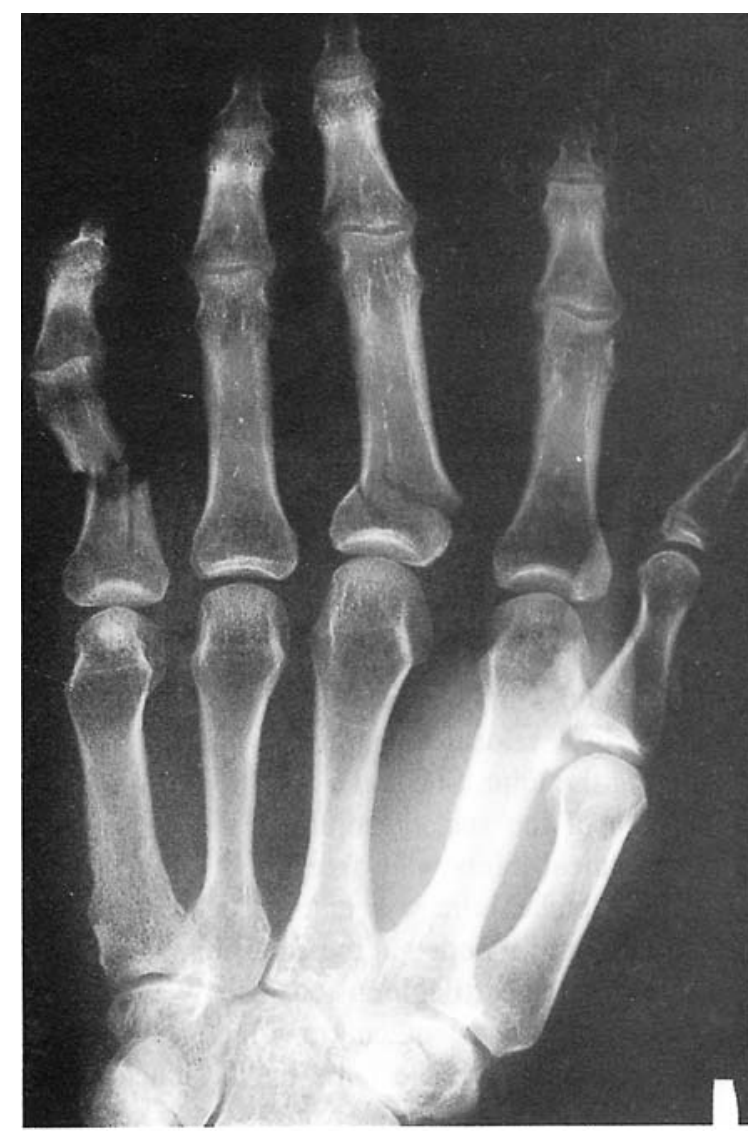

Fig. 1

G. E. B. Giddins, FRCS Orth, FRCS Ed, Consultant Orthopaedic Surgeon

Royal United Hospital, Combe Park, Bath BA1 3NG, UK.

P. D. Burge, FRCS, Consultant Hand Surgeon

John Radcliffe Hospital, Headley Way, Oxford OX3 9DU, UK

Correspondence to Mr P. D. Burge at the Nuffield Orthopaedic Centre NHS Trust, Windmill Road, Headington, Oxford OX3 7LD, UK.

(01996 British Editorial Society of Bone and Joint Surgery 0301-620X/96/2R61 \$2.00

J Bone Joint Surg [Br] 1996;78-B:325-6.

Received 1 May 1995; Accepted 28 June 1995 digital nerves and flexor tendons were intact but both digital arteries had been ruptured at the level of the distal end of the A2 pulley. The vessel ends of the radial digital artery were trimmed and repaired end-to-end giving good perfusion; patency was confirmed by a digital Allen's test after two months.

Case 2. A 14-year-old boy trapped his left hand between a bollard and a rope, sustaining closed fractures of the proximal phalanges of the middle, ring and little fingers (Fig. 2). Both digital arteries of the ring finger and the ulnar digital

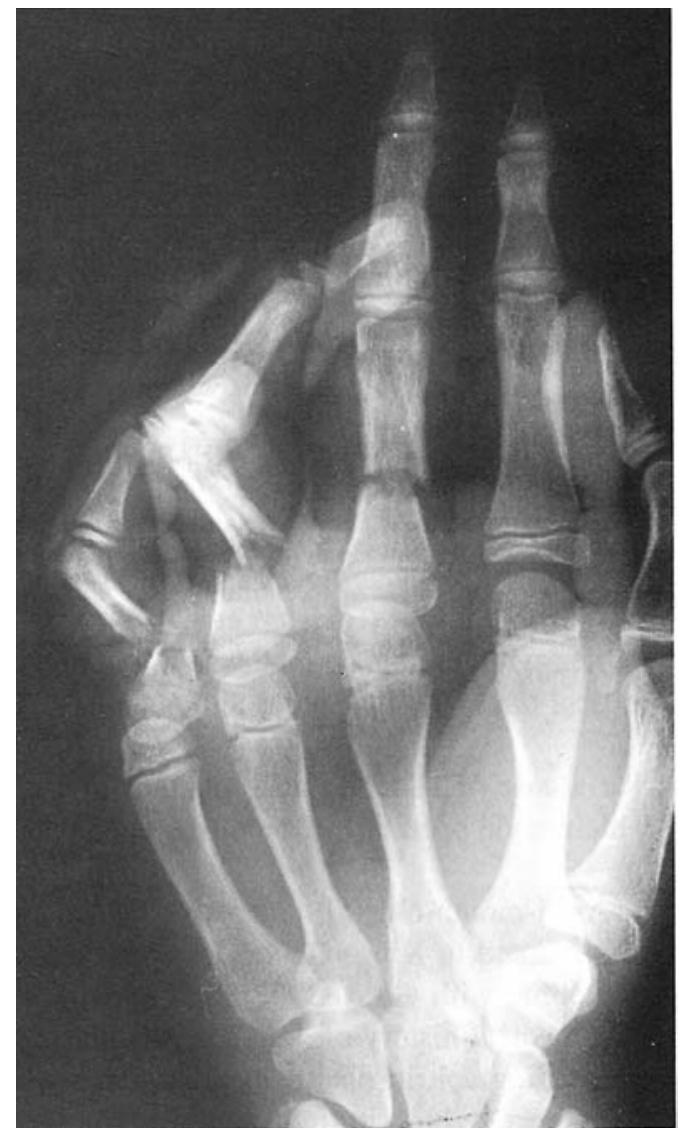

Fig. 2

artery of the little finger were ruptured at the level of the fractures, but the nerves and tendons were intact. The fractures were stabilised by open reduction and internal fixation, and both arteries of the ring finger were repaired end-to-end after excision of 1 to $2 \mathrm{~mm}$ of damaged vessel. Good perfusion was restored and both vessels remained patent at three months.

Case 3. A heavy piece of wood fell on to the dorsum of the dominant right hand of a ten-year-old girl as she performed a handstand, causing closed comminuted fractures of the 
proximal phalanges of the middle and ring fingers. At assessment at another hospital on the following morning, perfusion of the middle finger was poor and the digital pulses were absent on Doppler examination.

Exploration through midaxial incisions revealed thrombosis in the digital vessels at the level of the middle of the proximal phalanx. A 'fasciotomy' was performed on each side of the finger but no vascular or bone surgery was undertaken. The circulation improved slowly over five days and on the eighth day the fracture was stabilised with percutaneous pins which were removed after three weeks. The wounds healed after four weeks.

She presented to us nine months after the injury with an angular deformity causing digital overlap on flexion. Active movement was limited by flexor tendon adhesion and scar contracture. The finger was cool, capillary refilling was sluggish and the distal pulp was atrophic. Neither digital artery was patent on the digital Allen's test but sensation was normal.

Discussion. Lister (1993) reported that rupture of the digi- tal arteries may occur in closed phalangeal fractures, but we could find no other reference. The possibility of such closed vascular injury in the digits does not seem to be widely known, but its recognition is important; failure to repair the injured vessels, by vein graft if necessary, may have disastrous consequences for the digit. It is unwise to assume that the finger will be perfused adequately through collateral vessels; these may be compromised by injury and by swelling. Even if necrosis is avoided, the atrophic changes seen in case 3 are likely to impair function in the long term. It is especially important to recognise this repairable injury because the presence of intact digital nerves and flexor tendons offers the prospect of excellent functional recovery.

No benefits in any form have been received or will be received from a commercial party related directly or indirectly to the subject of this article.

\section{REFERENCE}

Lister G. The hand: diagnosis and indications. 3rd ed. New York: Churchill Livingstone, 1993:59.

\section{CONGENITAL VERTICAL TALUS WITH A TALOCALCANEAL COALITION}

\section{DAVID M. KLEIN, ANDREW A. MEROLA， CHARLES R. SPERO}

Talocalcaneal coalition has been recognised in association with peroneal spastic flat foot (Badelon et al 1984) and has also been reported with teratological club foot, but not with congenital vertical talus (CVT) (Spero, Simon and Tornetta 1994).

We describe a case of talocalcaneal coalition in a child with CVT, which made open reduction of the talonavicular joint difficult.

Case report. A 15-month-old full-term African-American female infant presented to Kings County Hospital paediatric orthopaedic clinic with a left CVT. She had no known diseases or past medical history of note. The diagnosis was confirmed on a radiograph in plantar flexion. Her toe and foot dorsiflexors were tight, with mild bowstringing of the tendons. Tendo Achillis and the peroneal tendons were also

D. M. Klein, MD, Clinical Assistant Instructor

A. A. Merola, MD, Chief Resident

C. R. Spero, MD, Professor

Department of Orthopaedics, SUNY Health Science Center at Brooklyn/ Kings County Hospital Center, Box 30, 450 Clarkson Avenue, Brooklyn, New York 11203, USA.

Correspondence to Professor C. R. Spero.

(C)1996 British Editorial Society of Bone and Joint Surgery

0301-620X/96/2R58 \$2.00

J Bone Joint Surg [Br] 1996;78-B:326-7.

Received 30 March 1995; Accepted 25 April 1995 tight. Neurological examination showed no other pathology and radiographs of her spine and hip were normal.

At operation, during the dissection of the medial aspect of her hind foot, we noted that the patient had an abnormally rigid talocalcaneal joint. No fluid was found on entering the joint. She had a coalition of the medial facet in the area of the sustentaculum. The anterior and posterior talocalcaneal joints were free.

The subtalar joint was entered posteriorly and followed medially until it ended at the coalition (Fig. 1). Using sharp dissection, the cartilaginous coalition was excised with care to preserve the sustentaculum (Fig. 2). At this point it was easy to manipulate the talus on the calcaneus. A free fat graft from the posterior part of the heel was packed into the space created by excision of the cartilaginous bridge.

The operation was then completed by reduction of the talonavicular and the calcaneocuboid joints and lengthening of the peroneal and digital extensor tendons and tendo Achillis. The medial and lateral columns of the foot were then immobilised with two $0.62 \mathrm{~mm}$ Kirschner wires. Reduction of the talus was confirmed on radiographs.

Discussion. We could find no report in the literature or in reviews of the larger series published on CVT of an association with tarsal coalition, despite the high frequency (up to 66\%; Dodge, Ashley and Gilbert 1987) of associated anomalies (Badelon et al 1984; Hamanishi 1984). At 15 